\title{
New lonic Conductor as Solid Electrolyte for Solid Oxide Fuel Cell Application
}

Reginaldo Ferreira and Marcos A.C. Berton

SENAI Institute of Innovation in Electrochemistry; CEP 80215-090, Av. Comendador Franco, 1341; Curitiba/PR, Brazil

\section{ABSTRACT}

In this work, ceria-doped electrolytes with general formula of $\mathrm{Ce}_{0.8} \mathrm{Y}_{0.2-}$ $\mathrm{La}_{\mathrm{x}} \mathrm{O}_{1.9}(\mathrm{x}=0.00 ; 0.05 ; 0.10 ; 0.15 ; 0.20)$ were synthesized by combustion method, using glycine as a fuel. The phase identification and morphology of the powders was studied by X-ray diffraction (XRD), surface area measurements (BET) and Raman spectroscopy. The consistency of particle sizes, calculated by the Scherrer formula, and BET measurements suggests that all as-synthesized powders were composed of weakly agglomerated crystallites. After the sintering process (1450 ${ }^{\circ} \mathrm{C} / 5 \mathrm{~h}$ ) all pellets reach relative densities above $94 \%$ of the theoretical density. The contributions of grains and grain boundaries to the total conductivity, were investigated by a.c. impedance spectroscopy, in temperature range of $200-500{ }^{\circ} \mathrm{C}$. The results show that the substitution of the yttrium by lanthanum mainly affects the grain boundary conductivity.

Key-words: doped-ceria, SOFC, solid electrolyte, fuel cells 


\section{INTRODUCTION}

The present work was presented in the INTERCORR 2013 in Portuguese language and is presented here by permission of Cigré-Brasil [1] and is a contribution to the First International Seminar on Innovation in Electrochemical Industry held in September, 2013 in Curitiba-PR, Brasil.

Solid oxide fuel cells (SOFCs) can provide high-energy conversion efficiency for a variety of applications ranging from large scale power plants to mobile applications for vehicles and portable electronics [2,3]. Yttria stabilized zirconia (YSZ), commonly used as an electrolyte material in SOFCs, requires temperatures above $800{ }^{\circ} \mathrm{C}$ for the cell operation, leading to high costs of interconnectors and other construction materials, as well as problems with thermal degradation and thermal expansion mismatch. To overcome these problems, great efforts have been made to lower the operating temperature of SOFCs to the temperature range of $500-700{ }^{\circ} \mathrm{C}$. At the present, materials based on doped ceria are considered the most promising electrolytes with sufficient electrical properties to operate in that temperature range $[4,5]$. Despite being an electronic conductor when exposed to reducing conditions at high temperatures $[6,7]$, doped ceria demonstrate considerable higher ionic conductivity at relatively lower temperatures in comparison to that of YSZ electrolyte. Among the various single dopant system studied, gadolinium [8] and samarium [9] have been reported as the most effective dopants for ceria in terms of maximization of the ionic conductivity. Aiming to further optimize the electrolyte properties, co-doping method has been tested and promising results have been reported for system such as $\mathrm{Ce}(\mathrm{Ca}, \mathrm{Sm}) \mathrm{O}_{2-\delta}[10], \mathrm{Ce}(\mathrm{Ca}, \mathrm{Gd}) \mathrm{O}_{2}$. [10], $\mathrm{Ce}(\mathrm{Sm}, \mathrm{La}) \mathrm{O}_{2-}$ [11], $\mathrm{Ce}(\mathrm{Sm}, \mathrm{Y}) \mathrm{O}_{2-\delta}[11]$ and $\mathrm{Ce}(\mathrm{Nd}, \mathrm{Sm}) \mathrm{O}_{2-\delta}[12]$. It is well established that to improve the ionic conductivity of doped ceria, radii mismatch between the dopant and the cerium should be minimum, leading to a low elastic strain in the crystal lattice. Furthermore, co-doping may also induces changes in the association enthalpy between oxygen vacancy and the dopant ions and alters the microstructure characteristics of the sintered pellets. Since $\mathrm{Y}^{3+}$ and $\mathrm{La}^{3+}$ have, respectively, smaller and larger ionic radius than $\mathrm{Ce}^{4+}$ [13], a suitable combination of these two ions should result in a minimum lattice strain.

In this work, nanopowders of yttrium and lanthanum co-doped ceria (CeYLa) were synthesized by combustion method. The dopant concentration was fixed at $20 \mathrm{~mol} \%$ in order to keep the oxygen vacancy concentration constant. The results of co-doping on the powders morphology, microstructure characteristics and ionic conductivity are presented and discussed. Although various studies have been published on co-doped ceria, most of them report the influence of the substitution of the dopants on the total ionic conductivity only. In this work, we evaluate the influence of the substitution of $\mathrm{Y}$ by La on the grain and grain boundary conductivities. 


\section{EXPERIMENTAL}

\subsection{Synthesis}

Powders with the general formula $\mathrm{Ce}_{0.8} \mathrm{Y}_{0.2-\mathrm{x}} \mathrm{La}_{\mathrm{x}} \mathrm{O}_{1.9}$, with $\mathrm{x}=0.00 ; 0.05$; 0.10; 0.15; 0.20 (hereafter CeYLa00, CeYLa05, CeYLa10, CeYLa15 and CeYLa20) were synthesized by the combustion method, using glycine as a fuel. The reagents used were cerium nitrate $\left(\mathrm{Ce}\left(\mathrm{NO}_{3}\right)_{3} \cdot 6 \mathrm{H}_{2} \mathrm{O}\right.$, Aldrich, $\left.99.9 \%\right)$, yttrium ni-

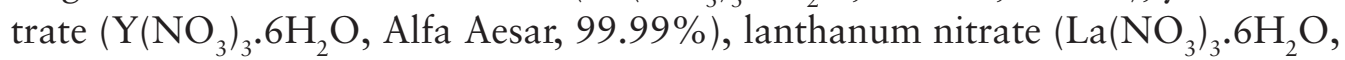
Merk, 99.99\%) and glycine $\left(\mathrm{C}_{2} \mathrm{NH}_{5} \mathrm{O}_{2}\right.$, Merck, 99.7\%). The starting materials were mixed in a desired proportion keeping the glycine to nitrate molar ratio equals to 0.53 . Stoichiometric amounts of the nitrates and glycine were dissolved in deionized water forming a transparent solution.

The resulting solution was stirred continuously for complete homogenization and heated in a hotplate to $90{ }^{\circ} \mathrm{C}$ to vaporize excessive water, forming a brown gel-like solution. After that, the temperature was elevated to 300

${ }^{\circ} \mathrm{C}$ and the combustion reaction took place. A detailed description of experimental procedures may be found elsewhere $[14,15]$. The resulting powders were calcined in air at $700{ }^{\circ} \mathrm{C}$ for 2 hours in order to remove the remaining organic reagent. Cylindrical pellets $(8 \mathrm{~mm})$ were prepared by uniaxial pressing at $98 \mathrm{MPa}$ followed by sintering in air for 5 hours at $1450^{\circ} \mathrm{C}$.

\subsection{Characterization}

The crystal structure of the powders and pellets were determined by X-ray diffraction, using a Phillips X'pert diffractometer with $\mathrm{Ni}$-filtered $\mathrm{Cu} \mathrm{K}$ radiation $(\lambda=154190 \AA)$, operating at $40 \mathrm{kV}$ and $40 \mathrm{~mA}$, at room temperature. Scans angle ranged from $20^{\circ} \leq 2 \theta \leq 90^{\circ}$ with a step size of $0.02^{\circ}$ for $1 \mathrm{~s}$. The lattice parameters of the sintered samples were calculated by fitting the observed reflections using a least squares refinement method (CellRef ${ }^{@} \mathrm{~V} 3$ program). The average crystallite size was calculated from the XRD peak [ $\left.\begin{array}{lll}1 & 1 & 1\end{array}\right]$ using the Scherrer equation. The surface area of the calcined powders was measured using Brunauer-Emmett-Teller (BET) nitrogen adsorption method (Quantachorme NOVA 1200). Before the BET analysis, the samples were outgassed for 1 hour at $100{ }^{\circ} \mathrm{C}$ to eliminate volatile adsorbents on the surface. The Raman spectra of the calcined powders were obtained using a Renishaw Raman Microscope System 3000. The excitation radiation employed was $632.8 \mathrm{~nm}$ of a He-Ne laser and a 50x objective lens was used to collect the back scattered light. The densities of the sintered pellets were calculated by Archimedes' method, using distilled water. Scanning Electron Micrographs were taken on the surface of the sintered specimens using scanning electron microscopy (XL30, Philips). Grain size distribution was estimated by the intercept method [16]. 
Electrical conductivity of the sintered specimens was measured by ac impedance spectroscopy, using a Frequency Response Analyzer (Solartron, 1260), on symmetric cell configuration. Silver paste electrodes were painted onto the sintered dense pellet surfaces and fired at $400{ }^{\circ} \mathrm{C}$ for $30 \mathrm{~min}$. The measurements were conducted in the $5 \mathrm{~Hz}-13 \mathrm{MHz}$ frequency range with a $100 \mathrm{mV}$ alternate signal. Measurements were taken in air, in the temperature range of $200-500{ }^{\circ} \mathrm{C}$. The data analysis was performed using the software package ZView (Scribner Associates Inc., Southern Pines, NC).

\section{RESULTS AND DISCUSSION}

The phase composition of the as-synthesized powders was studied using the X-ray diffraction. The diffraction patterns are presented in Fig. 1. All powders were single phase with cubic fluorite structure (ICDD Card 00-034-0394). No crystalline phase corresponding to $\mathrm{Y}_{2} \mathrm{O}_{3}$ or $\mathrm{La}_{2} \mathrm{O}_{3}$ was found which suggest that even without a calcining step the solid solution, at least partially, was formed during the combustion reaction.

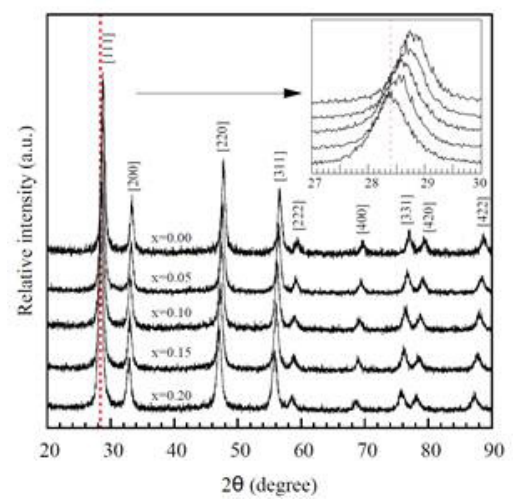

Figure 1. X-ray diffraction patterns of $\mathrm{Ce}_{0.8} \mathrm{Y}_{0.2-\mathrm{x}} \mathrm{La}_{\mathrm{x}} \mathrm{O}_{1.9}$ as synthesized powders.

The crystallite size of the calcined powders, estimated using the Scherrer equation, and the results of the BET analysis are shown in the Table 1. The average of the crystallite size obtained in this work is in good agreement with those reported in the literature for a similar condition of synthesis $[15,17,18]$. The consistency of particle sizes determined by X-ray analysis and BET surface measurements suggests that powders were composed of weakly agglomerated crystallites. Considering the nonsystematically change in the crystallite size and the surface area, it can be conclude that the substitution of $\mathrm{Y}^{3+}$ by $\mathrm{La}^{3+}$ play little influence on this parameters. 


\begin{tabular}{|c|c|c|c|c|c|c|}
\hline Composition & $\mathbf{a}(\mathbf{A})$ & $\mathbf{D}_{\text {drx }}(\mathbf{n m})$ & SBET $(\mathbf{m} 2 / \mathbf{g})$ & DBET $(\mathbf{n m})$ & $\mathbf{G}(\mathbf{m m})$ & pr (\%) \\
\hline CeYLa00 & 5.4031 & 25.6 & 25.1 & 35.0 & 1.32 & 94.6 \\
\hline CeYLa05 & 5.4205 & 23.7 & 30.8 & 28.4 & 1.31 & 95.6 \\
\hline CeYLa10 & 5.4380 & 23.1 & 31.6 & 27.5 & 1.07 & 95.7 \\
\hline CeYLa15 & 5.4542 & 23.7 & 29.8 & 29.0 & 1.16 & 95.7 \\
\hline CeYLa20 & 5.4749 & 21.5 & 31.8 & 27.1 & 1.50 & 97.1 \\
\hline
\end{tabular}

Table 1. Values of lattice parameter $(a)$, crystallite size $\left(D_{d r x}\right)$, specific surface area $\left(S_{B E T}\right)$, particle size calculated from the specific surface measurements $\left(D_{B E T}\right)$, grain size $(G)$, and relative density $\left(r_{r}\right)$.

Fig. 2 shows the XRD reflections of the sintered pallets. The lattice parameter was calculated by fitting the nine XRD reflections peaks of the five sintered samples. As can be seen from the Fig. 3, the substitution of the Yttrium by the Lanthanum induces a linear increase of the lattice parameter due to the difference of the ionic radius of the dopants, $\mathrm{Y}^{3+}=1.019 \AA$ [12] and $\mathrm{La}^{3+}=1.160 \AA$ [13]. This linear behavior suggests that the dopants were incorporated into the $\mathrm{Ce}^{4+}$ sites and the solid solutions were formed.

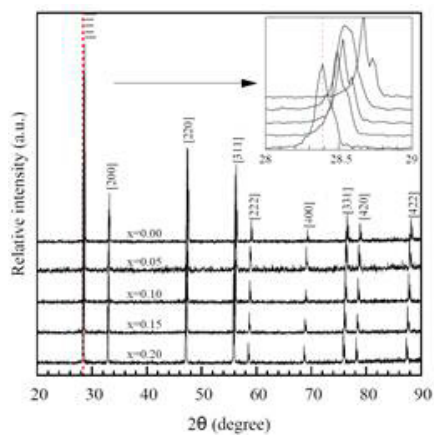

Figure 2. X-ray diffraction patterns of $\mathrm{Ce}_{0.8} \mathrm{Y}_{0.2-\mathrm{x}} \mathrm{La}_{\mathrm{x}} \mathrm{O}_{1.9}$ sintered pellets.

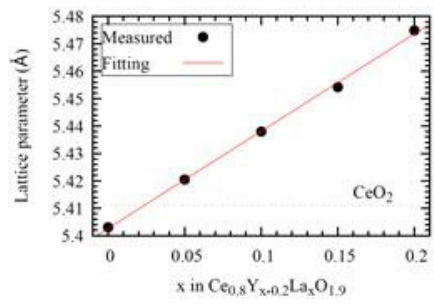

Figure 3. The dependence of the lattice parameter on the composition of doped ceria electrolytes.

Fig. 4 shows the Raman spectra of the calcined powders. Raman spectral features of the doped ceria are quite different when different excitation laser lines are used. This occurs due the distinct detection depth of the excitation laser which reflects the inhomogeneous distribution of dopants in the sample [19, 20]. For 
this reason we used a $632.8 \mathrm{~nm}$ excitation laser line that reflects both the interior and the surface information of the sample due to the weak absorption of the La and Y doped ceria at this wavelength [19].

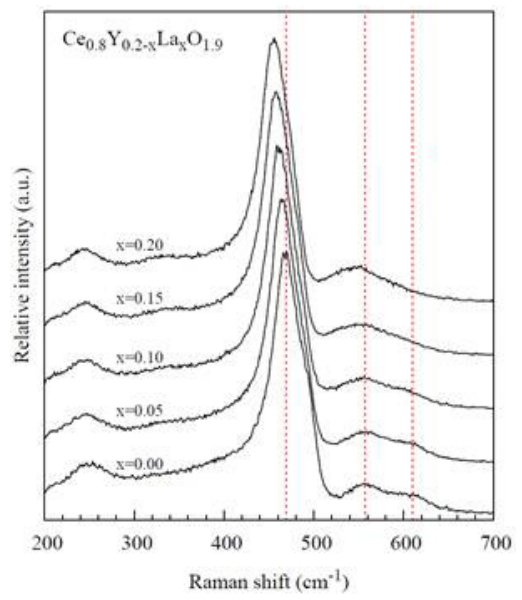

Figure 4: Raman spectra of $\mathrm{Ce}_{0.8} \mathrm{Y}_{0.2-\mathrm{x}} \mathrm{La}_{\mathrm{x}} \mathrm{O}_{1.9}$ calcined powders.

The Raman mode observed nearly $460 \mathrm{~cm}^{-1}$ is attributed to $\mathrm{F}_{2 \mathrm{~g}}$ vibrational mode, which is characteristic of fluorite structure. With the increase of $\mathrm{La}^{3+}$ content, a shift to lower frequencies of the $\mathrm{F}_{2 \mathrm{~g}}$ band position can be observed. According to McBride et al. [21] this shift is related to the difference in the lattice parameter and with the increase in concentration of oxygen vacancies. The two additional bands around $550 \mathrm{~cm}^{-1}$ and $610 \mathrm{~cm}^{-1}$ are related to the presence of defect sites in the fluorite structure. The band at $\sim 550 \mathrm{~cm}^{-1} \mathrm{can}$ be ascribed to the $\mathrm{O}^{2-}$ vacancies introduced as defects to keep charge neutrality due to the replacement of $\mathrm{Ce}^{4+}$ by $\mathrm{M}^{3+}$ cations in the structure of the solid [21,22]. With the substitution of yttrium by lanthanum, the band at $\sim 610 \mathrm{~cm}^{-1}$ disappears. This band has been related to the presence of $\mathrm{MO}_{8}$-type complex defect, that occurs as a result of the difference between the ionic radius of dopants and the radius of $\mathrm{Ce}^{4+}$ [19]. From these results it is possible to verify the effective incorporation of the oxygen vacancies in the $\mathrm{CeO}_{2}$ crystalline structure.

After the sintering step $\left(1450{ }^{\circ} \mathrm{C} / 5 \mathrm{~h}\right)$ all pellets reach relative densities above $94 \%$ of the theoretical density. Fig. 5 shows the SEM images of surfaces of the sintered pellets. The main microstructural characteristics of the samples are grains with uniform morphology and shape, with a large distribution of grain sizes. Although the sintering temperature was lower than that usually employed to obtain high densification of doped ceria ceramics, no significant intergranular porosity was detected, indicating a relatively high sinterability of these powders. The average grain size $G$, determined by the intercept method [15], and the relative densi- 
ties are presented in Table 1. It is well known that ultrafine ceria powders, with a large surface area, possess a high sintering activity resulting in high densification of the sintered bodies. This tendency can be clearly observed in Fig. 6, confirming that densification is greater for pellets made from powders with finer particle size.

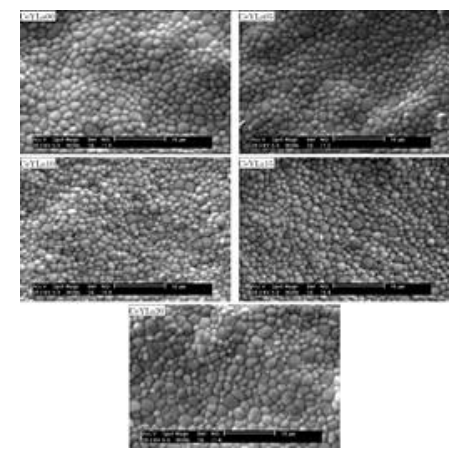

Figure 5. SEM images of surfaces of the sintered pellets at $\left(1450^{\circ} \mathrm{C} / 5 \mathrm{~h}\right)$.

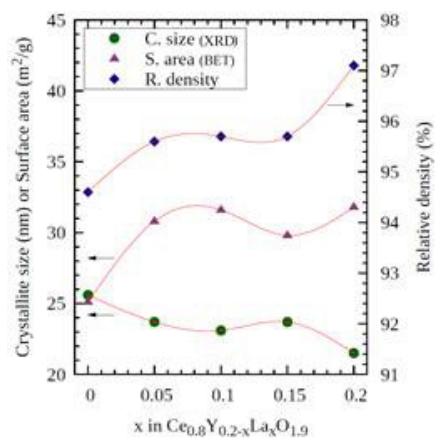

Figure 6. Relative density, crystallite size and surface area as a function of the composition of doped ceria.

\subsection{Impedance}

The ac impedance analysis was employed to evaluate the electrical properties of the pellets. Based on an electrical circuit model, the impedance spectra allowed separation of grain and grain boundary contribution to the conductivity. A typical impedance diagram, conducted at $263^{\circ} \mathrm{C}$, for pellets sintered at $1450{ }^{\circ} \mathrm{C}$, is shown in Fig 7, where the real part (Z') is plotted against the imaginary part (Z”) as a parametric function of frequency $(\omega)$. Numbers in this diagram represent the logarithm of the frequency, in Hz. The first high frequency semicircle corresponds to the intragranular electrical behavior, associated with bulk resistance $\mathrm{R}_{\mathrm{b}}$. The second semicircle, in the intermediate frequency range, corresponds to the grain boundary electrical behavior which is associated with the grain boundary resistance $R_{\mathrm{gb}}$. A third semicircle (not shown in the Fig 7), in the low frequency range, is typically visible in temperatures above $450{ }^{\circ} \mathrm{C}$ and corresponds to the electrolyte-electrodes interface reactions, being associated with the electrode resistance $\mathrm{R}_{\mathrm{ct}}$. 


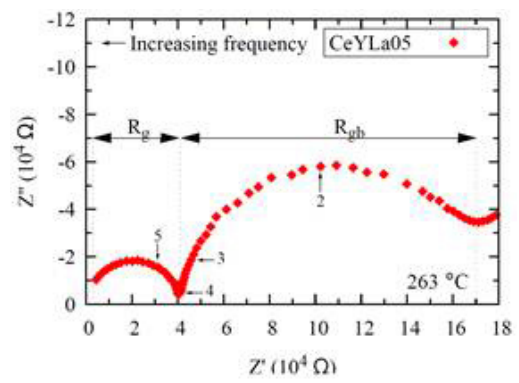

Figure 7. Impedance diagram of $\mathrm{Ce}_{0.8} \mathrm{Y}_{0.15} \mathrm{La}_{0.05} \mathrm{O}_{1.9}$ pellet sintered at $1450^{\circ} \mathrm{C}$ for 5 hours.

Due to lower activation energy of electrode process than the bulk and grain boundary activation energies, the third part of the spectra becomes dominating as the temperature rises. Thus, in order to measure the grain and grain boundary conductivity, the measurement temperature was kept below $500{ }^{\circ} \mathrm{C}$.

The total ionic resistance $R_{t}$ was calculated as a sum of the bulk resistance $\left(R_{b}\right)$ and the grain boundary resistance $\left(R_{g b}\right)$. The electrical conductivity was calculated from the resistance values, using L/RS allowing to obtain the Arrhenius plots using traditional Arrhenius equation:

$$
\sigma=\frac{\sigma_{0}}{T} \exp \left(-\frac{E_{0}}{k T}\right)
$$

where $\sigma_{0}$ is the pre-exponential factor; $\mathrm{E}_{0}$, the activation energy for the process; $\mathrm{k}$, the Boltzmann constant; and $\mathrm{T}$, the absolute temperature. As the densities of all samples were comparable (Table 1) no correction for the porosity values was applied. The Arrhenius plot of the grain, grain boundary and total conductivity of the samples are shown in Fig 8. The activation energies, calculated from the slopes of the Arrhenius plots, are shown in Table 2.

\begin{tabular}{|c|c|c|c|}
\hline \multirow{2}{*}{ Composition } & \multicolumn{3}{|c|}{ Activation energy (eV) (200-500 oC) } \\
\cline { 2 - 4 } & Bulk & G. Boundary & Total \\
\hline CeYLa00 & 1.014 & 1.087 & 1.069 \\
\hline CeYLa05 & 0.978 & 1.072 & 1.046 \\
\hline CeYLa10 & 0.917 & 1.049 & 0.993 \\
\hline CeYLa15 & 0.911 & 1.023 & 0.957 \\
\hline CeYLa20 & 0.864 & 1.023 & 0.984 \\
\hline
\end{tabular}

Table 2. Activation energy of the electrical conductivity in the $200-500^{\circ} \mathrm{C}$ range. 


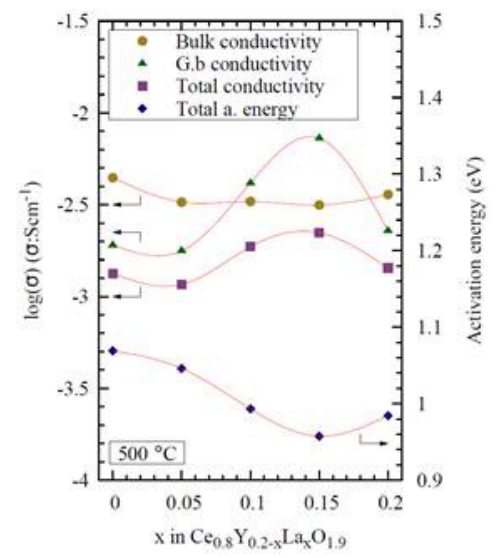

Figure 8. The electrical conductivity, measured at $500^{\circ} \mathrm{C}$, and activation energy $\left(200-500^{\circ} \mathrm{C}\right)$ as a function of the composition of doped ceria electrolytes.

Table 3 shows the calculated values of the grain and the grain boundary conductivities at $300{ }^{\circ} \mathrm{C}$ and $500{ }^{\circ} \mathrm{C}$. The higher total conductivity occurs at the lanthanum concentration of $\mathrm{x}=0.10$ and $\mathrm{x}=0.15$, i.e. $\mathrm{Ce}_{0.8} \mathrm{Y}_{0.10} \mathrm{La}_{0.10} \mathrm{O}_{1.9}$ and $\mathrm{Ce}_{0.8} \mathrm{Y}_{0.05} \mathrm{La}_{0.15} \mathrm{O}_{1.9}$ apparently have higher total conductivity than the singly doped samples with same dopant concentration ( $20 \mathrm{~mol} \%$ trivalent metal) in the temperature range of $200-500{ }^{\circ} \mathrm{C}$. To illustrate the electrical conductivity changes upon co-doping, Fig. 9 presents the values of the bulk, grain boundary and total conductivity, at $500{ }^{\circ} \mathrm{C}$, as a function of the amount of the second dopant. It is evident from Fig. 9 that the substitution of the $\mathrm{Y}^{+3}$ by $\mathrm{La}^{+3}$ mainly affects the grain boundary conductivity. These results indicate that co-doping with an optimum ratio of yttrium and lanthanum can further improve the total conductivity of ceria electrolytes by increasing the grain boundary conductivity.

\begin{tabular}{|c|c|c|c|c|c|c|}
\hline \multirow{2}{*}{ Temperature } & \multicolumn{7}{|c|}{ Electrical conductivity $\left(10^{-3} \mathbf{S c m}^{-1}\right)$} \\
\cline { 2 - 7 } & Contribution & CeYLa00 & CeYLa05 & CeYLa10 & CeYLa15 & CeYLa20 \\
\hline \multirow{3}{*}{$300\left({ }^{\circ} \mathrm{C}\right)$} & Bulk & 0.029 & 0.026 & 0.036 & 0.035 & 0.052 \\
\cline { 2 - 7 } & G. Boundary & 0.008 & 0.008 & 0.022 & 0.046 & 0.014 \\
\cline { 2 - 7 } & Total & 0.006 & 0.006 & 0.013 & 0.019 & 0.011 \\
\hline \multirow{3}{*}{$500\left({ }^{\circ} \mathrm{C}\right)$} & Bulk & 4.431 & 3.265 & 3.291 & 3.147 & 3.591 \\
\cline { 2 - 7 } & G. Boundary & 1.904 & 1.775 & 4.148 & 7.277 & 2.280 \\
\cline { 2 - 7 } & Total & 1.334 & 1.160 & 1.867 & 2.226 & 1.431 \\
\hline
\end{tabular}

Table 3. The electrical conductivity at $300^{\circ} \mathrm{C}$ and $500^{\circ} \mathrm{C}$. 

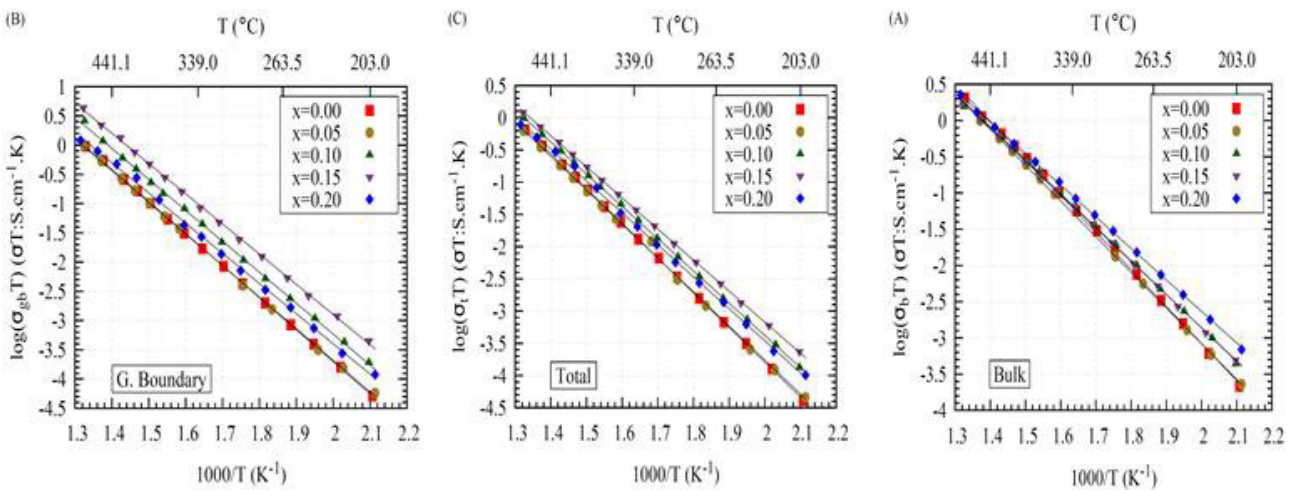

Figure 9. Arrhenius plots of the bulk (A), grain boundary (B) and total (C) electrical conductivity of sintered pellets.

All Arrhenius plots are essentially linear indicating that only one mechanism dominates the ionic conduction in the temperature range analyzed. Figure 8-(A) shows that the differences in the bulk conductivities become smaller as the temperature approaches $500{ }^{\circ} \mathrm{C}$. In contrast, Figure 8-(B) shows that co-doped samples CeYLa10 and CeYLa15 have significantly higher grain boundary conductivity than the singly doped samples in the whole temperature range of measurement.

The activation energy (Table 2) of the bulk and grain boundary decrease with the addition of lanthanum. However, in the total activation energy, CeYLa15 is an exception. The changes of the activation energy of total conductivity on composition, shown in Fig. 9, seem to be well correlated with the variations of total conductivity - the maximum values of total conductivity corresponds to the minimum energy activation. The activation energies values found in this work are in general agreement with the literature data for ceria based electrolytes.

\section{CONCLUSIONS}

Homogeneous solid solutions of yttrium and lanthanum co-doped cerium oxides were obtained by the combustion technique using glycine as a fuel. XRD results revealed that all as-synthesized powders were single phase with cubic fluorite structure. The average crystallite sizes, calculated by Scherrer formula, were between $21.5 \mathrm{~nm}$ and $25.6 \mathrm{~nm}$. The consistency of particle sizes determined by $\mathrm{X}$-ray analysis and BET surfaces measurements suggests that powders were composed of weakly agglomerated crystallites. After the sintering step at $1450{ }^{\circ} \mathrm{C} / 5 \mathrm{~h}$ all pellets reach relative densities above $94 \%$ of the theoretical density with no significant intergranular porosity. The higher total conductivity, in the temperature range of $200-500{ }^{\circ} \mathrm{C}$, was observed for CeYLa10 and CeYLa15 samples. The results presented in this paper indicated that co-doping with appropriate ratio of yttrium and lanthanum leads to an improvement of the total ionic conductivity by 
increasing the grain boundary conductivity of ceria based electrolyte compared to that of Y or La single doped.

\section{REFERENCES}

[1] http://www.cigre.org.br

[2] E. Fabbri, D. Pergolesi, E. Traversa, Materialsw challenges toward proton-conducting oxide fuel cells: a critical review, Chemical Society Reviews 39 (11) (2010) 4355-4369.

[3] R. Muccillo, E. N. S. Muccillo, F. C. Fonseca, Y. V. Franca, T. C. Porfirio, D. Z. de Florio, M. A. C. Berton, C. M. Garcia, Development and testing of anode-supported solid oxide fuel cells with slurry-coated electrolyte and cathode, Journal of Power Sources 156 (2) (2006) 455-460.

[4] S. Haile, Fuel cell materials and components, Acta Materialia 51 (19) (2003) 5981-6000.

[5] J. W. Fergus, Electrolytes for solid oxide fuel cells, Journal of Power Sources 162 (1) (2006) 30-40.

[6] I. Naik, T. Tien, Small-polaron mobility in nonstoichiometric cerium dioxide, Journal of Physics and Chemistry of Solids 39 (3) (1978) 311- 315.

[7] B. Dalslet, P. Blennow, P. Hendriksen, N. Bonanos, D. Lybye, M. Mogensen, Assessment of doped ceria as electrolyte, Journal of Solid State Electrochemistry 10 (8) (2006) 547-561.

[8] B. Steele, Appraisal of $\mathrm{Ce}_{1-\mathrm{y}} \mathrm{Gd}_{\mathrm{y}} \mathrm{O}_{2-\mathrm{y} / 2}$ electrolytes for IT-SOFC operation at 500 degrees ${ }^{\circ} \mathrm{C}$, Solid State Ionics 129 (1-4) (2000) 95-110.

[9] K. Eguchi, T. SetoguchiI, T. Inoue, H. Arai, Electrical-properties of ceriabased oxides and their application to solid oxide fuel-cells, Solid State Ionics 52 (1-3) (1992) 165-172.

[10] M. Dudek, A. Rapacz-Kmita, M. Mroczkowska, M. Mosialek, G. Mordarski, Co-doped ceria-based solid solution in the $\mathrm{CeO}_{2}-\mathrm{M}_{2} \mathrm{O}_{3}-\mathrm{CaO}, \mathrm{M}=\mathrm{Sm}$, Gd system, Electrochimica Acta 55 (14, SI) (2010) 4387-4394.

[11] M. Dudek, W. Bogusz, L. Zych, B. Trybalska, Electrical and mechanical properties of $\mathrm{CeO}_{2}$-based electrolytes in the $\mathrm{CeO}_{2}-\mathrm{Sm}_{2} \mathrm{O}_{3}-\mathrm{M}_{2} \mathrm{O}_{3}(\mathrm{M}=\mathrm{La}, \mathrm{Y})$ system, Solid State Ionics 179 (1-6) (2008) 164-167.

[12] S. Omar, E. D. Wachsman, J. C. Nino, Higher conductivity $\mathrm{Sm}^{3+}$ and $\mathrm{Nd}^{3+}$ co-doped ceria-based electrolyte materials, Solid State Ionics 178 (37-38) (2008) 1890-1897.

[13] R. Shannon, Revised effective ionic-radii and systematic studies of inter- 
atomic distances in halides and chalcogenides, Acta Crystallographica Section A 32 (SEP1) (1976) 751-767.

[14] K. Singh, S. A. Acharya, S. S. Bhoga, Glycine-nitrates combustion synthesis and properties of nano-sized $\mathrm{Ce}_{1-\mathrm{x}} \mathrm{Gd}_{\mathrm{x}} \mathrm{O}_{2 \text {-delta }}$ solid solution for solid oxide fuel cell viewpoint, Indian Journal of Engineering and Materials Sciences 13 (6) (2006) 525-530.

[15] R. Purohit, B. Sharma, K. Pillai, A. Tyagi, Ultrafine ceria powders via glycine-nitrate combustion, Materials Research Bulletin 36 (15) (2001) 27112721.

[16] M. Mendelson, Average grain size in polycrystalline ceramics, Journal of the American Ceramic Society 52 (8) (1969) 443+.

[17] R. K. Lenka, T. Mahata, P. K. Sinha, A. K. Tyagi, Combustion synthesis of gadolinia-doped ceria using glycine and urea fuels, Journal of Alloys and Compounds 466 (1-2) (2008) 326-329.

[18] D. H. Prasad, J.-W. Son, B.-K. Kim, H.-W. Lee, J.-H. Lee, A significant enhancement in sintering activity of nanocrystalline $\mathrm{Ce}_{0.9} \mathrm{Gd}_{0.1} \mathrm{O}_{1.95}$ powder synthesized by a glycine-nitrate-process, Journal of Ceramic Processing Research 11 (2) (2010) 176-183.

[19] L. Li, F. Chen, J.-Q. Lu, M.-F. Luo, Study of Defect Sites in $\mathrm{Ce}_{1-\mathrm{x}} \mathrm{M}_{\mathrm{x}} \mathrm{O}_{2 \text { - }}$ $(\mathrm{x}=0.2)$ Solid Solutions Using Raman Spectroscopy, Journal of Physical Chemistry A 115 (27) (2011) 7972-7977.

[20] M. Luo, Z. Yan, L. Jin, M. He, Raman spectroscopic study on the structure in the surface and the bulk shell of $\mathrm{Ce}_{\mathrm{x}} \operatorname{Pr}_{1-\mathrm{x}} \mathrm{O}_{2 \text {-(delta) }}$ mixed oxides, Journal of Physical Chemistry B 110 (26) (2006) 13068-13071.

[21] J. McBride, K. Hass, B. Poindexter, W. Weber, Raman and x-ray studies of $\mathrm{Ce}_{1-\mathrm{x}} \mathrm{Re}_{\mathrm{x}} \mathrm{O}_{2-\mathrm{y}}$, where $\mathrm{Re}=\mathrm{La}, \mathrm{Pr}, \mathrm{Nd}, \mathrm{Eu}, \mathrm{Gd}$, and Tb, Journal of Appplied Physics 76 (4) (1994) 2435-2441.

[22] W. Y. Hernandez, O. H. Laguna, M. A. Centeno, J. A. Odriozola, Structural and catalytic properties of lanthanide ( $\mathrm{La}, \mathrm{Eu}, \mathrm{Gd})$ doped ceria, Journal of Solid State Chemistry 184 (11) (2011) 3014-3020. 
